\title{
Non steroidal anti-inflammatory drugs in the prevention of cystoid macular edema after uneventful cataract surgery
}

\author{
This article was published in the following Dove Press journal: \\ Clinical Ophthalmology \\ 25 June 2014 \\ Number of times this article has been viewed
}

\author{
Nicolás E Quintana* \\ Alejandro R Allocco* \\ Julia A Ponce* \\ Mauricio GB Magurno \\ Instituto Santa Lucía, Paraná, \\ Argentina \\ *These authors contributed equally \\ to this work
}

Background: Cystoid macular edema (CME) remains an important complication after cataract surgery. There is no consensus about how to prevent this frequent complication. The purpose of this study was to conceive an effective anti-inflammatory strategy using nonsteroidal anti-inflammatory drugs (NSAIDs) together with regular treatment with corticosteroids to prevent $\mathrm{CME}$ and improve visual acuity after cataract surgery in patients without risk factors.

Materials and methods: We searched the PubMed, Cochrane, and Google Scholar databases focused on prospective, controlled, randomized, double-blind clinical trials published in the last 10 years, with a minimum follow-up of 4 weeks.

Results: A total of nine clinical trials, one systematic review, and two reviews satisfied our search criteria. Most studies highlighted that NSAIDs are as powerful as corticosteroids to diminish postoperative inflammation, and demonstrated an additional benefit when used in combination with standard corticosteroid postsurgical therapy. In addition, the use of NSAIDs in the perioperative period seems to significantly improve the outcome after surgery and helps prevent CME in low-risk patients.

Conclusion: The prophylactic use of NSAIDs in combination with the standard postoperative steroid scheme appears to be a positive course of action for preventing CME after cataract surgery. We suggest a therapeutic scheme based on the administration of one drop four times a day, beginning the day before surgery and for 4 weeks after the procedure. It is also advisable to administer one drop every 15 minutes in the hour prior to surgery in order to obtain better anti-inflammatory efficacy.

Keywords: cystoid macular edema, non-steroidal anti-inflammatory drugs, cataract surgery, NSAIDs, CME

\section{Introduction}

Cystoid macular edema (CME) remains an important complication after cataract surgery and other ophthalmological interventions. Nowadays, it is the main cause of decreased visual acuity after these procedures, even in patients without risk factors or in uneventful cataract surgery. Based on the literature consulted, the incidence of clinical CME varies from $0.1 \%$ to $2 \%$ in patients without risk factors. ${ }^{1}$ However, some clinical trials have reported up to $9 \%$ angiographic CME and increased mean foveal thickness measured by optical coherence tomography. ${ }^{2}$

Although the exact pathogenesis of CME is yet to be fully elucidated, some theories have been put forward. The most accepted one involves intraocular inflammation with prostaglandin (PG) release as the most important factor, which would
Allocco

Instituto Santa Lucía, Alameda de la Federación 493, Paraná 3100 , Entre Ríos, Argentina

Tel/Fax +543434233496

Email ale_allocco@outlook.com 
break the hemato-ocular barrier, increasing its permeability with subsequent passage of liquid to the subfoveal space. ${ }^{3-5}$ This is the reason corticosteroids and non-steroidal antiinflammatory drugs (NSAIDs) are used to treat CME.

The excellent anti-inflammatory effect of steroids is based on their ability to inhibit phospholipase $A_{2}$, which reduces the production of PGs and leukotrienes by inhibiting both the cyclooxygenase (COX) and lipoxygenase pathways. ${ }^{6,7}$ On the other hand, although NSAIDs only inhibit COX, they provide a very good anti-inflammatory effect apart from the key advantages of maintaining intraoperative mydriasis and postoperative pain under control. ${ }^{4,8}$ Based on their mechanism of action, steroids seem to be more powerful than NSAIDs, since they act in a preliminary step in the inflammatory cascade. In any case, limitations in the use of steroids must be acknowledged because of their frequent and dangerous side effects, in contrast to the extraordinary safety profile presented by NSAIDs. ${ }^{3}$

The aforementioned effects of both corticosteroids and NSAIDs seem to be further maximized when these drugs are used in combination for the management of postoperative inflammation, producing a synergistic effect, which represents an excellent therapeutic strategy to consider. ${ }^{6,9}$ There is, however, little consensus in the field of ophthalmology about which of the NSAIDs is the one with the best pharmacokinetic and pharmacodynamic properties and which one is able to reach the inflammatory focus more easily - in this case, on the retina - so as to become ophthalmologists' NSAID of choice when talking about the prevention and/or treatment of CME. In the same manner, it is not stipulated when this therapy should be started in relation to the surgical intervention so that an optimal drug concentration in the vitreous humor can be obtained, increasing its anti-inflammatory efficacy.

The purpose of the present study was to conceive an effective anti-inflammatory strategy using NSAIDs together with regular treatment with corticosteroids to prevent $\mathrm{CME}$, and improve visual acuity after cataract surgery in patients without risk factors based on the analysis of the results of clinical trials conducted under different conditions as reported in the literature.

\section{Materials and methods}

The PubMed, Cochrane, and Google Scholar databases were searched, delving first into the effectiveness of the current alternatives with steroids and NSAIDs for the prevention and treatment of CME. Then, the focus was shifted onto the characteristics of the different NSAIDs to shed further light on their optimal use within an effective strategy. The search terms used were "pseudophakic cystoid macular edema", "cystoid macular edema treatment", "NSAIDs on cystoid macular edema", "steroid on cystoid macular edema", and "cystoid macular edema prevention". The inclusion criteria were prospective, controlled, randomized, double-blind clinical trials published in the last 10 years, with a minimum follow up of 4 weeks. Finally, a total of nine clinical trials, one systematic review, and two reviews satisfied our search criteria.

\section{Results}

In relation to the effectiveness of the use of steroids and NSAIDs, in a prospective cohort, Mathys and Cohen ${ }^{2}$ evaluated macular thickness and best-corrected visual acuity after cataract surgery in a group that received only standard treatment with moxifloxacin and prednisolone acetate and in a study group to which nepafenac $0.1 \%$ was added. It must be emphasized that both the control and study groups had received three nepafenac drops immediately before surgery. They found no significant differences in the groups, and concluded that it is not necessary to add postoperative NSAIDs when they are used in the preoperative period.

Unlike those results, substantial visual improvement in the postsurgical period was reported by Miyake et $\mathrm{al}^{1}$ in a study that compared the postoperative use of nepafenac $0.1 \%$ with fluorometholone $0.1 \%$ for 5 weeks. The study group that received nepafenac had thinner foveal thickness at the end of the trial, as well as presenting an earlier visual recovery and less flare in the anterior chamber. This outcome points to superior effectiveness of nepafenac in controlling postsurgical inflammation.

In a prospective multicenter trial with 546 eyes, Wittpenn et $\mathrm{al}^{10}$ evaluated if the addition of perioperative ketorolac tromethamine $0.4 \%$ to standard treatment with prednisolone improves the outcome in patients without risk factors for CME. Patients were randomized into two groups: one that only received postoperative prednisolone four times a day and another that received ketorolac four times a day for 3 days preoperatively. Also, both groups received four doses of ketorolac 1 hour before surgery. Results in this clinical trial showed that none of the patients in the ketorolac group had clinical CME, while five in the control group suffered this complication. Similarly, whereas an optical coherence tomography scan showed evidence of CME in six patients in the control group, no cases in the ketorolac group displayed this condition. The authors concluded that the addition of perioperative ketorolac to postoperative 
prednisolone significantly reduces the incidence of $\mathrm{CME}$ in low-risk patients.

Toward the development of an effective strategy to treat CME patients, it is important at this point to look into the pharmacokinetic and pharmacodynamic characteristics of NSAIDs, as well as their power and effectiveness to decrease postoperative inflammation and pain. In a comparative trial, Bucci et al ${ }^{11}$ studied the power of ketorolac and nepafenac in the inhibition of prostaglandin $\mathrm{E}_{2}\left(\mathrm{PGE}_{2}\right)$ and their concentration in aqueous humor. They concluded that ketorolac is more effective in its capability to inhibit $\mathrm{PGE}_{2}$ and also to reach higher concentration levels in the anterior chamber. However, Bucci et al's findings were challenged by Walters et $\mathrm{al}^{9}$ on the grounds of study-design limitations in a prospective multicenter double-blind clinical trial comparing the pharmacokinetics and pharmacodynamics of nepafenac, ketorolac and bromfenac. Walters concluded that nepafenac has better bioavailability because of its prodrug property as well as the greater power of amfenac, the active drug in it, to inhibit COX2.

In contrast to those results, Almeida et al ${ }^{12}$ found no significant differences between these NSAIDs in a clinical trial that evaluated the effectiveness of nepafenac and ketorolac against placebo in 162 eyes. The therapy scheme was one drop four times daily beginning 24 hours prior to surgery, and maintaining this scheme for 4 weeks after surgery. The results showed no significant differences in the three groups. The researchers concluded that prophylactic NSAIDs are not necessary in patients with no risk factors and after uncomplicated surgeries.

In a prospective multicenter double-blind trial with 227 patients, Nardi et $\mathrm{al}^{6}$ compared the power of nepafenac and ketorolac against placebo. Results demonstrated that both NSAIDs have greater anti-inflammatory efficacy than placebo, and also confirmed that nepafenac is as good as ketorolac at preventing postsurgical pain and ocular inflammation, but with better tolerance on the part of patients.

In a recent systematic review, Yilmaz et $\mathrm{al}^{4}$ analyzed four randomized controlled clinical trials, two of which compared ketorolac with an untreated control group, and two that assessed ketorolac versus placebo. They arrived at the conclusion that ketorolac treatment significantly reduces the risk of developing CME after 4 weeks of treatment.

\section{Discussion}

Based on the evidence presented, there is a significant additive anti-inflammatory effect of NSAIDs when used in combination with standard corticosteroid postsurgical therapy. As well as this, the use of NSAIDs in the perioperative period seems to significantly improve the outcome after surgery and helps prevent CME in low-risk patients. Regarding the different options of NSAIDs available, current studies highlight nepafenac as the one with better bioavailability and greater anti-inflammatory efficacy, as well as being the most comfortable drop for the patient.

In conclusion, a prophylactic use of NSAIDs in combination with the standard postoperative steroid scheme appears to be a positive course of action for preventing CME after cataract surgery. The recommended scheme is one drop four times a day beginning the day before surgery and for 4 weeks after the procedure. It is also advisable to administer one drop every 15 minutes in the hour prior to surgery so as to obtain better anti-inflammatory efficacy. Furthermore, this regime could provide additional benefits for surgery, such as maintaining intraoperative mydriasis, diminishing tyndall, pain, and improving postoperative corneal edema. This scheme should be reassessed in the case of patients with risk factors for $\mathrm{CME}$ or complicated cataract surgeries.

\section{Acknowledgment}

We would like to express our deepest gratitude to Carlos Bantar and Graciela E Yugdar Tófalo for their valuable collaboration in the preparation of this manuscript.

\section{Disclosure}

The authors report no conflicts of interest in this work.

\section{References}

1. Miyake K, Ota I, Miyake G, Numaga J. Nepafenac $0.1 \%$ versus fluorometholone $0.1 \%$ for preventing cystoid macular edema after cataract surgery. J Cataract Refract Surg. 2011;37(9):1581-1588.

2. Mathys KC, Cohen KL. Impact of nepafenac $0.1 \%$ on macular thickness and postoperative visual acuity after cataract surgery in patients at low risk for cystoid macular oedema. Eye (Lond). 2010;24(1): 90-96.

3. Reddy R, Kim SJ. Critical appraisal of ophthalmic ketorolac in treatment of pain and inflammation following cataract surgery. Clin Ophthalmol. 2011;5:751-758.

4. Yilmaz T, Cordero-Coma M, Gallagher MJ. Ketorolac therapy for the prevention of acute pseudophakic cystoid macular edema: a systematic review. Eye (Lond). 2012;26(2):252-258.

5. Elsawy MF, Badawi N, Khairy HA. Prophylactic postoperative ketorolac improves outcomes in diabetic patients assigned for cataract surgery. Clin Ophthalmol. 2013;7:1245-1249.

6. Nardi M, Lobo C, Bereczki A, et al. Analgesic and anti-inflammatory effectiveness of nepafenac $0.1 \%$ for cataract surgery. Clin Ophthalmol. 2007;1(4):527-533.

7. Rho DS. Treatment of acute pseudophakic cystoid macular edema: diclofenac versus ketorolac. J Cataract Refract Surg. 2003;29(12): 2378-2384.

8. Sandoval HP, Fernández de Castro LE, Vroman DT, Solomon KD. A review of the use of ketorolac tromethamine $0.4 \%$ in the treatment of post-surgical inflammation following cataract and refractive surgery. Clin Ophthalmol. 2007;1(4):367-371. 
9. Walters T, Raizman M, Ernest P, Gayton J, Lehmann R. In vivo pharmacokinetics and in vitro pharmacodynamics of nepafenac, amfenac, ketorolac, and bromfenac. J Cataract Refract Surg. 2007;33(9): 1539-1545.

10. Wittpenn JR, Silverstein S, Heier J, Kenyon KR, Hunkeler JD, Earl M. A randomized, masked comparison of topical ketorolac $0.4 \%$ plus steroid vs steroid alone in low-risk cataract surgery patients. Am J Ophthalmol. 2008;146(4):554-560.
11. Bucci FA Jr, Waterbury LD, Amico LM. Prostaglandin E2 inhibition and aqueous concentration of ketorolac $0.4 \%$ (Acular LS) and nepafenac $0.1 \%$ (Nevanac) in patients undergoing phacoemulsification. Am J Ophthalmol. 2007;144(1):146-147.

12. Almeida DR, Khan Z, Xing L, et al. Prophylactic nepafenac and ketorolac versus placebo in preventing postoperative macular edema after uneventful phacoemulsification. J Cataract Refract Surg. 2012;38(9): $1537-1543$.

\section{Publish your work in this journal}

Clinical Ophthalmology is an international, peer-reviewed journal covering all subspecialties within ophthalmology. Key topics include: Optometry; Visual science; Pharmacology and drug therapy in eye diseases; Basic Sciences; Primary and Secondary eye care; Patient Safety and Quality of Care Improvements. This journal is indexed on

\section{Dovepress}

PubMed Central and CAS, and is the official journal of The Society of Clinical Ophthalmology (SCO). The manuscript management system is completely online and includes a very quick and fair peer-review system, which is all easy to use. Visit http://www.dovepress.com/ testimonials.php to read real quotes from published authors. 